\title{
Las sanciones administrativas en Italia: un problema de Derecho constitucional
}

Pasquale Cerbo ${ }^{1}$

Sumario: I. PRESENTACIÓN. II. INTRODUCCIÓN. III. LAS SANCIONES ADMINISTRATIVAS. PRINCIPIOS CONSTITUCIONALES. IV. EL PRINCIPIO DE LEGALIDAD. V. EL PRINCIPIO DE PERSONALIDAD. VI. EL PROCEDIMIENTO SANCIONADOR. 1. El justo procedimiento y la relación con la regulación general del procedimiento administrativo. 2. El procedimiento sancionador en la ley 689/1981. VII. LAS DISCIPLINAS ESPECIALES: EN PARTICULAR, LA LEGISLACIÓN REGIONAL. VIII. LA TUTELA JURISDICCIONAL. IX. EL PRINCIPIO DE PROPORCIONALIDAD: ¿HACIA MODELO DIFERENTE DE SANCIÓN ADMINISTRATIVA?

\section{PRESENTACIÓN ${ }^{2}$}

El profesor Pasquale Cerbo nos expone en su trabajo los principales problemas jurídicos que plantea la institución de las sanciones administrativas en el ordenamiento italiano. El lector español podrá seguir sin especial dificultad el riguroso análisis que nos ofrece el citado autor de la problemática de las sanciones administrativas en Italia, ya que los puntos de partida sobre los que se construye dicha institución son de hecho semejantes en nuestro sistema y el italiano. Pero también es cierto que existen algunas significativas diferencias entre ambos sistemas, lo que sin duda hace atractivo este estudio comparado.

Un primer punto común entre ambos ordenamientos sancionadores administrativos es la inspiración que ambos sistemas buscan en el derecho penal, como ordenamiento de referencia obligado cuando se trata de construir de un derecho represivo y garantizador. Otro punto común es la trascendencia que tiene la Constitución para fijar los principios que han de regir la potestad sancionadora de la administración en sus aspectos formales y materiales. La Constitución y el derecho penal son, por tan-

1 Università Católica del Sacro Cuore. Piacenza.

2 La traducción e introducción al trabajo del profesor Pasquale Cerbo corresponden a Joaquín Tornos Mas, Catedrático de Derecho Administrativo de la Universidad de Barcelona. 
to, en un país y en otro, las normas de cabecera del derecho sancionador administrativo, las normas a las que se acude para buscar los principios y los supraconceptos legales en base a los cuales ir construyendo una potestad administrativa necesaria, pero cuyo ejercicio debe estar especialmente sometido a normas previas y control posterior.

A partir de estas notas comunes surgen de inmediato las diferencias. Así, en el caso italiano la Constitución no contiene referencia alguna al derecho sancionador administrativo, mientras que en el caso español, aunque ciertamente las referencias son escasas, al menos si está reconocida esta potestad. No obstante este silencio de la Constitución italiana, jurisprudencia y doctrina no han dudado en buscar el anclaje de la potestad sancionadora administrativa, y sus límites, en el texto de la Constitución a través de otros preceptos. Por otro lado, el ordenamiento italiano cuenta con una ley general en materia de sanciones administrativas (la ley 681 de 1981), lo que no ocurre en nuestro sistema, en el que el régimen general cuenta tan sólo con unos pocos artículos en la ley 30/1992. Por último, y como consecuencia de la peculiaridad del sistema de control de los actos administrativos en Italia, en este país la impugnación de las sanciones se lleva a cabo por lo general ante la jurisdicción ordinaria, en la medida en que la sanción afecta a un derecho subjetivo.

Como decíamos la reflexión comparada sobre nuestros sistemas normativos en materia de sanciones administrativas ofrece aspectos de indudable interés. Destacaremos algunas de las cuestiones que plantea el trabajo que presentamos siguiendo el orden expositivo del mismo.

El concepto de sanción administrativa se construye en el sistema italiano a partir del texto constitucional pero a través de un razonamiento que podemos calificar de recorrido inverso. Es decir, la Constitución establece las notas esenciales que caracterizan a la sanción penal. Estas notas son la existencia de una reserva absoluta de ley para poder privar o limitar la libertad personal y la exigencia de un procedimiento judicial para poder imponer una medida de estas características. De acuerdo con estas notas, que caracterizan a la sanción penal, se ha construido el concepto de sanción administrativa, lo que ha llevado a concluir que este tipo de sanción incluye toda pena que no puede afectar a la libertad personal o de domicilio, y que se impone a través de un procedimiento administrativo. Por tanto, la sanción administrativa es la que comporta una prestación patrimonial o personal y que es fruto de un expediente administrativo. El proceso judicial en estos casos es eventual, es decir, dependerá de si el sancionado impugna o no el acto sancionador de la administración.

Una segunda nota importante es la diferente configuración del principio de legalidad o, más propiamente, del alcance de la reserva de ley en esta materia. En el caso italiano la reserva legal se ha producido de hecho por la congelación del rango que ha dispuesto la ley 689/1981. Es esta ley la que establece en su artículo primero que "na62 die puede ser sancionado administrativamente si no es en base a una ley que haya entrado en vigor con anterioridad a la comisión de la infracción”. Consecuentemente, 
si no hay un marco constitucional de referencia, una ley ordinaria posterior puede alterar esta previsión, y puede admitir remisiones amplias a la potestad reglamentaria para tipificar conductas y determinar las correspondientes sanciones.

El autor del trabajo desarrolla en este punto unas interesantes consideraciones sobre la amplia remisión efectuada en el sistema italiano a las ordenanzas locales para poder tipificar conductas y sanciones. A diferencia de nuestro caso, en el que el Tribunal Constitucional, para justificar que una ordenanza local pueda tipificar infracciones y sanciones, ha tenido que construir la teoría según la cual si la sanción local se aprueba por el pleno de la corporación se cumple con la finalidad última de la reserva de ley (esto es, que sea la asamblea representativa de la colectividad la que se impone sus propias sanciones), en el caso italiano esta argumentación es inexistente. La ley local ha remitido prácticamente en blanco a los alcaldes y presidentes de los entes provinciales la tipificación de infracciones y determinación de sanciones, con el único límite de la cuantía de 500 euros. En ejercicio de esta amplia habilitación la imaginación de los titulares de la potestad sancionadora local se ha desbordado, y en el trabajo se nos da cuenta de la amplia variedad de hechos que han pasado a ser tipificados como infracciones. El autor concluye que de hecho se está ante una concepción débil del principio de legalidad.

Frente a esta realidad de un principio de legalidad débil la jurisprudencia ha tratado de reforzarlo acudiendo para ello al texto constitucional. Ante la falta de una referencia precisa a la materia sancionadora administrativa en la Constitución italiana los tribunales han recurrido a otros preceptos constitucionales con la finalidad de imponer una reserva legal en esta materia. Así, la jurisprudencia ha acudido al artículo 23 en el que se establece que "sólo podrán imponerse prestaciones personales o patrimoniales con arreglo a la ley" (precepto que se corresponde con nuestro artículo constitucional 31,1). Si la sanción administrativa es precisamente la que se caracteriza por imponer este tipo de prestaciones, la jurisprudencia concluye que la ley, cuando remite al reglamento la definición de la conducta infractora y de la correspondiente sanción, no puede hacerlo en blanco, y debe fijar unos mínimos contenidos.

Por último queremos destacar un argumento que nos ha parecido especialmente singular para oponerse a una amplia potestad sancionadora local. Se afirma que no es admisible que la entidad local imponga una sanción pecuniaria cuando será ella misma la que se beneficie de este pago.

El tratamiento del elemento personal de las sanciones sigue totalmente lo establecido en el sistema penal, lo que comporta la prohibición de sancionar a personas jurídicas y la exigencia de dolo o culpa en el infractor (lo que en el trabajo se denomina el elemento psicológico de la sanción).

No obstante esta referencia general a los principios del derecho penal la fuerza de los hechos ha llevado a relativizar estos principios, y poco a poco se ha ido admitiendo la sanción a personas jurídicas, particularmente en materia de regula- 
ción económica. De nuevo aquí, el hecho de que el principio de personalidad se contenga en la ley $681 / 1981$ no impide que por leyes posteriores se relativice dicho principio.

También en el aspecto procedimental merecen destacarse algunas singularidades que afectan en este caso a la teoría general de las normas y a la relación entre las normas estatales y regionales. Así, una primera cuestión deriva de la existencia en Italia de una ley general en materia de sanciones, la ya citada ley 681/1981. Como consecuencia de ello, y teniendo también en cuenta que posteriormente se aprobó una ley general sobre el procedimiento administrativo, la ley 241/1990, se planteó el tema de qué ley debía regular el procedimiento sancionador, la ley especial previa, o la general posterior. Finalmente el Tribunal de Casación en pleno (Sentencia de 27 de abril de 2006), determinó que debía aplicarse la ley de 1981, que no obstante ser una ley especial contenía en materia procedimental las garantías suficientes.

La segunda cuestión es la relativa a la relación entre la ley estatal y la regional. La ley sancionadora italiana 681/1981 no se puede equiparar a una ley básica estatal. Por tanto ¿podrán las leyes regionales sancionadoras establecer diferentes procedimientos sancionadores? Sobre esta cuestión la jurisprudencia ha afirmado que la potestad sancionadora no es una materia competencial y su ejercicio debe entenderse vinculado a la potestad material. Por tanto, en los casos en los que la competencia material sobre la que se aplica el régimen sancionador sea de competencia exclusiva autonómica, la región podrá establecer su propio procedimiento sancionador.

En cuanto a las cuestiones propiamente procedimentales el trabajo examina los aspectos relativos al valor de las actas, el pago reducido anticipado, el derecho de audiencia y la motivación.

En lo concerniente a la tutela judicial ya hemos apuntado que lo más destacado es el hecho de que como consecuencia de la singularidad del sistema italiano (la distinción entre el derecho subjetivo e interés legítimo para acceder a la jurisdicción ordinaria o a la contencioso-administrativa) las sanciones administrativas se impugnan como regla general ante la justicia ordinaria, si bien en algunos casos el recurso deberá interponerse ante la jurisdicción administrativa. Esta distinción lleva al autor del trabajo a destacar los diferentes niveles de intensidad en el control de la sanción impuesta, ya que el alcance revisor de la decisión administrativa es mayor cuando quien controla es la justicia ordinaria, a la que incluso se permite que pueda llegar a sustituir la sanción impuesta. Este diferente nivel de protección es criticado y se alzan voces en defensa de una igualdad de trato independientemente de cual sea la jurisdicción competente.

Por último el autor nos expone la creciente importancia del principio de proporcionalidad en el proceso aplicativo de las sanciones y, en relación con esta cuestión, se apuntan unas consideraciones interesantes sobre la posible graduación por parte 64 de la administración del ejercicio de su potestad. Esto es, la determinación por crite- 
rios de oportunidad de en qué casos y con qué intensidad debe recurrirse a la aplicación de las medidas sancionadoras 3 .

\section{INTRODUCCIÓN}

Los estudios generales sobre las sanciones administrativas en Italia se ocupan preferentemente del examen de la ley 24 de noviembre de 1981, cuyo título primero contiene la disciplina general de este instituto ${ }^{4}$, abordando todos sus aspectos más importantes, es decir, las reglas sustanciales, el procedimiento y la tutela jurisdiccional.

La ley 689/1981 establece, sin lugar a dudas, una formulación muy precisa para la sanción administrativa, regulándola en modo análogo a la sanción penal. Según la citada ley en el ordenamiento italiano la sanción administrativa comparte con la sanción penal la naturaleza de "pena en sentido estricto" o "pena en sentido técnico".

La sanción sirve para disuadir de cometer nuevos ilícitos tanto al trasgresor singular (prevención especial), como a la generalidad de las personas (prevención general). El hecho de que ambos tipos de sanción cumplan la misma función - y por tanto no tenga sentido aplicarlas de forma acumulativa- se confirma por la aplicación del principio de especialidad. Cuando un mismo hecho está castigado por una regla penal y por una disposición que prevé una sanción administrativa se aplica la regla de carácter especial5.

De acuerdo con esta configuración legislativa la sanción administrativa se diferencia claramente de algunas figuras afines, como las medidas restitutivas (que también se aplican por la administración en caso de vulneración de normas). Con este tipo de medidas la administración no persigue el fin de castigar al responsable del ilí-

3 El profesor Pasquale Cerbo es en la actualidad Ricercattore di diritto amministrativo en la Universidad Católica del Sacro Cuore, con sede en Piacenza, y es un reconocido especialista en el estudio de las sanciones administrativas en el ordenamiento italiano. De entre sus numerosas publicaciones destacamos las siguientes:

- Le sanzioni amministrative, ed. Giuffré, Milán 1999, con un apéndice de puesta al día del año 2000.

- La Corte di giustizia e il codice dell strada: problema di disparità di trattamento per i veicoli non immatriculati in Italia, en "Il Foro italiano", julio-agosto 2002.

- Successioni di leggi nel tempo e applicazione Della disciplina piú favorevoli per gli autori di violazioni amministrative, en "Il Foro italiano", mayo 2003.

- Le sanzione amministrative, en la obra colectiva dirigida por S. Cassesse, "Trattato di diritto administrativo”, Tomo I, ed. Giuffré, Milán 2003.

- Sanzioni amministrative, en el "Dizionario di Diritto pubblico", dirigido por S. Cassesse, ed. Giuffré, Milán 2006.

— Sanzioni amministrative, en “Il diritto, enciclopedia giuridica del Sole 24 hore”, vol. 14, 2007.

- El título Sanzioni amministrative dentro de la obra colectiva dirigida por M.Cammelli, "Il codice dei beni culturali e del paessaggio", Il Mulino 2007, Bolonia.

4 EL artículo. 12 de la ley n. 689/1981 establece que las disposiciones contenidas en la ley "son de aplicación, siempre que no se haya excluido dicha aplicación, a todas las infracciones para las que esté prevista una sanción administrativa consistente en el pago de una cantidad de dinero".

$5 \quad$ Cfr. el art. 9, 1, ley n. 689/1981. 
cito, sino la restauración de la situación de ilegalidad material derivada de una vulneración de la norma. La medida restitutiva sirve desde esta perspectiva para restablecer la situación de hecho (la legalidad material) modificada por la infracción, pero no tiene como fin castigar al responsable del ilícito en ejercicio de una función de prevención general y especial.

La importancia de la disciplina contenida en la ley 689/1981 para la comprensión del instituto de la sanción administrativa no debe hacer olvidar un dato fundamental: las sanciones administrativas plantean principalmente problemas de derecho constitucional. Por ello son necesarias algunas precisiones.

Muchas disposiciones de la Constitución italiana se ocupan de la "pena" y de su función. En primer lugar el artículo 25,2 establece que nadie puede ser castigado si no es en base a una ley que haya entrado en vigor antes de la comisión del hecho enjuiciado. En segundo lugar, el artículo 27,1 dispone que "la responsabilidad penal es personal". En tercer lugar el artículo 27,3 establece que "las penas no pueden consistir en tratamientos contrarios a la dignidad humana y deben tender a la reeducación del condenado".

Sin embargo, según la doctrina de la Corte Constitucional, estas disposiciones sólo se aplican a las sanciones penales ${ }^{6}$, sin que sean de aplicación a otras tipologías de sanciones, en particular a las sanciones administrativas. Es más, lo cierto es que en la Constitución italiana las infracciones y las sanciones administrativas no son objeto de atención de forma expresa (a diferencia de lo que ocurre en los artículos 25,1 y 45,3 de la Constitución española). Según una lectura muy superficial podría, por tanto, parecer que la Constitución italiana ignora completamente las sanciones administrativas no obstante dichas sanciones ya hubieran estado ampliamente contempladas en leyes preconstitucionales.

Las razones de este silencio constitucional no son claras y seguramente el tratar de descubrir hoy dichas razones no tendría grandes consecuencias interpretativas. Pero lo que si puede afirmarse con seguridad es que los problemas de las sanciones en el ordenamiento italiano son principalmente, por no decir exclusivamente, problemas de derecho constitucional. En efecto, por un lado la aplicación de las sanciones (también las no penales) afecta a derechos de las personas constitucionalmente protegidos y, por otro lado, el hecho de que la sanción se imponga por poderes públicos implica siempre el tener que aplicar los principios constitucionales que rigen la actividad de las administraciones públicas.

\section{LAS SANCIONES ADMINISTRATIVAS. PRINCIPIOS CONSTITUCIONALES}

En el ordenamiento italiano el concepto de sanción administrativa deriva, aunque sólo sea por su diferencia con el concepto de sanción penal, de las disposiciones constitucionales. 
Si aceptamos como significado del concepto "sanción" la aplicación de una pena por la violación de un precepto, el problema que se nos plantea en primer lugar es determinar sobre qué derechos pueden incidir las sanciones administrativas. A diferencia de la Constitución española, cuyo artículo 25,3 prohíbe expresamente a la Administración imponer sanciones que incidan sobre la libertad personal, la Constitución italiana no contiene ninguna prohibición expresa sobre esta cuestión. Por esta razón se podría pensar en establecer una diferenciación meramente nominal entre sanción penal y administrativa, pero lo cierto es que no es así. Del contenido constitucional emerge una clara distinción entre los dos tipos de sanción.

Debe partirse del artículo 13 de la Constitución, precepto que establece una reserva de ley absoluta y una reserva de jurisdicción para las penas consistentes en la privación o limitación de la libertad personal, lo que supone que sólo el juez (y exclusivamente en los casos y formas previstos en la ley), puede imponer estas sanciones. A sensu contrario, las sanciones impuestas por sujetos diversos del juez (en particular por las administraciones públicas) o en su caso fuera de un proceso penal no pueden nunca comportar una restricción de la libertad personal del sancionado (ni tampoco de otras libertades fundamentales como la de domicilio, reguladas por la Constitución italiana de forma análoga a la libertad personal, vid. al respecto, el artículo 14).

En otras palabras, según lo que establece la Constitución, algunos bienes jurídicos (como la libertad personal o la de domicilio) tan sólo pueden ser afectados por sanciones aplicadas por un juez y como consecuencia de un procedimiento judicial dotado de fuertes garantías, lo que sólo cumple el proceso penal7. Por esta razón la jurisprudencia ha destacado en ocasiones que las sanciones administrativas se caracterizan "por la ausencia de toda posible incidencia de la sanción que se imponga sobre la libertad personal del individuo" ${ }^{8}$. Estas sanciones pueden en cambio incidir sobre otros derechos, esto es, pueden consistir en prestaciones patrimoniales personales, como el pago de cantidad de dinero (sanción pecuniaria); adquisición coactiva de bienes para el patrimonio de la administración (confiscación), pérdida temporal o definitiva de alguna habilitación o estatus (sanción de prohibición).

De todos modos la afectación sobre derechos de esta naturaleza también está sujeta por la Constitución a una reserva de ley. De hecho, según el artículo 23 de la Constitución, "ninguna prestación personal o patrimonial puede ser impuesta si no es en base a la ley". Esta reserva, sin embargo, a diferencia de la que contiene el artículo 13, tiene carácter relativo y admite en cierto modo la remisión a fuentes subordinadas a la ley (como reglamentos, actos administrativos generales o particulares, etc.).

7 Téngase en cuenta que estas prescripciones afectan también a las sanciones penales pecuniarias, que pueden convertirse -en caso de incumplimiento- en la sanción de libertad controlada- (art. 102 ley n. 689/1981), lo que supone por tanto una limitación de la libertad personal.

8 Cass., sez. I, 19 noviembre 1996, n. 10137.

9 Como ha señalado la doctrina el art. 23 Cost. está redactado de un modo completamente general: no distingue por tanto los casos en los que a la prestación se añada o no una sanción. 
Por otra parte, ya que no está prevista ninguna reserva de jurisdicción, no es indispensable un procedimiento jurisdiccional para la imposición de estas sanciones, a diferencia de lo que ocurre en los casos en que se afecte a la libertad personal y de domicilio $^{10}$. Las sanciones administrativas pueden ser, por ello, aplicadas en base a un procedimiento administrativo. El proceso en su caso será sucesivo y, por tanto, tiene carácter eventual, en el sentido de que corresponde a los sujetos sancionados decidir si activan o no el proceso jurisdiccional.

No obstante encontrarse con un cuadro constitucional de referencia poco homogéneo, con respecto al existente para las sanciones penales, el legislador, al tener que diseñar las reglas generales de las sanciones administrativas, ha reproducido los principios cardinales del derecho penal. En particular, en el Título primero de la ley $689 / 1981$ se incorporan el principio de legalidad en sentido estricto (artículo 1) y el principio de personalidad de las sanciones (artículos 2 y siguientes). La indiscutible impronta penalística que asume la sanción administrativa en función de lo dispuesto en esta ley no puede hacer olvidar, sin embargo, el diverso rango de las fuentes que establecen estos principios. La Constitución para las sanciones penales, la ley ordinaria para las sanciones administrativas. Precisamente a la luz de esta diversidad de planos normativos serán examinados los aspectos principales de las sanciones administrativas.

\section{EL PRINCIPIO DE LEGALIDAD}

El artículo 1 de la ley 689/1981 establece que "nadie puede estar sujeto a sanciones administrativas si no es en base a una ley que haya entrado en vigor antes de la comisión de la infracción".

Se trata de un principio que recoge de forma literal lo establecido para las sanciones penales en el artículo 25,2 de la Constitución ("nadie puede ser castigado si no es base a una ley que haya entrado en vigor antes de la comisión del hecho imputado"). Parece ser aplicable a ambos tipos de sanciones el brocardo "nullum crimen nulla poena sine lege". Sólo la ley puede por tanto tipificar los ilícitos (penales y administrativos) y las correspondientes sanciones según la concepción clásica de la reserva absoluta de ley.

La jurisprudencia, sin embargo, ha tendido a destacar la diferencia que existe entre las sanciones penales y las sanciones administrativas. Para las primeras el principio de legalidad estricta o absoluta tiene un fundamento constitucional. Para las segundas tiene tan sólo un fundamento legal'11. Esta constatación posee especial im-

10 La competencia del juez penal -en base al art. 24 ley n. 689/1981- está prevista sólo cuando no sea posible acreditar la existencia del ilícito penal sin previamente acreditar la existencia del ilícito adminis68 trativo

11 Cass., sez I, 6 noviembrre 1999, n 12367. 
portancia en el momento de determinar en qué debe consistir la habilitación legislativa de la potestad sancionadora.

Es opinión compartida que, sin perjuicio de esta diferencia, el poder sancionador no tiene carácter originario, ni puede considerarse implícito en la atribución de una determinada función administrativa. La potestad sancionadora requiere una atribución legal expresa. Lo confirma la jurisprudencia según la cual, en ausencia de una ley que así lo prevea, no son sancionables las violaciones de normas reglamentarias ${ }^{12}$. Con el mismo fundamento se afirma que las administraciones no pueden ampliar de forma analógica, en base a circulares propias, los ámbitos de aplicación de las previsiones sancionadoras contenidas en una ley ${ }^{13}$.

La diferencia de fuentes incide en otro aspecto. Es recurrente en la jurisprudencia la afirmación de que el carácter legislativo (y no constitucional) de la reserva de ley para las sanciones administrativas comporta que leyes posteriores a la de 1981 pueden contener reenvíos a fuentes de rango sublegislativo para la definición de los ilícitos administrativos, derogando de esta forma el artículo 1 de la ley 689/1981 ${ }^{14}$. De acuerdo con este criterio se ha considerado admisible no sólo que la ley contenga reenvíos a reglamentos o a otras fuentes subordinadas para la integración de aspectos de orden técnico de la conducta prohibida (lo que está incluso permitido en el derecho penal), sino incluso que la ley reenvíe "en todo" a fuentes sublegislativas la definición de los comportamientos sancionables. En otras palabras, la ley se limita a afirmar que quedan sujetas a sanción administrativa las violaciones de reglamentos u otros actos, los cuales definen posteriormente la conducta prohibida.

Así ocurre, por ejemplo, con las vulneraciones de las normas de conducta establecidas por las entidades locales (municipios y provincias). Reproduciendo en lo esencial el esquema de leyes preconstitucionales, una norma con valor de ley ordinaria (el artículo 7-bis del texto único de los entes locales ${ }^{15}$ ), ha establecido que la violación de los reglamentos de los entes locales y de las ordenanzas de los alcaldes y presidentes de las provincias serán castigadas con una sanción administrativa graduable entre un mínimo y un máximo (de 25 a 500 euros). Los reglamentos y las ordenanzas serán las normas que determinen las conductas prohibidas y por tanto sujetas a sanción.

Originariamente esta previsión se estableció para cubrir un vacío normativo. De hecho, como consecuencia de la abrogación de la vieja ley sobre los entes locales y a falta de una disposición análoga en el nuevo texto único, las violaciones de los regla-

12 Cfr. Cons. Stato, sez. I, 17 octubre 2001, n. 885.

13 Cass., sez. II, 22 mayo 2007, n. 11826.

14 Cass., sez. I, 27 agosto 1999, n. 8986; Cass., sez. II, 26 abril 2006, n. 9584; TAR Lazio, sez. III, 22 junio 2006, n. 5038.

15 Art. 7-bis decreto legislativo 18 agosto 2000, n. 267, introducido por el art. 16 ley 16 enero 2003, n. 3 
mentos municipales o provinciales no eran sancionables ${ }^{16}$. Se trataba, de forma principal, de violación de reglamentos en materias de competencia local legislativamente definidas. De hecho, en base al artículo 117, 6 de la Constitución los municipios y las provincias regulan mediante reglamentos la organización y el desarrollo de las funciones que tienen atribuidas por ley. Aun siendo numerosas, las materias de las que pueden tratar los reglamentos locales son las previstas en la ley (estatal o regional), ya que se entiende que sólo la ley puede atribuirles una determinada función.

Recientemente, en el marco de una política dirigida a dar a los municipios mayores poderes en materia de seguridad pública, la ley ha atribuido a los Alcaldes el poder de adoptar ordenanzas, con contenido normativo, con el fin de "prevenir y eliminar el grave peligro que amenaza la integridad física de la población y la seguridad municipal”" Bajo la consideración no de órganos locales, sino actuando como agentes del Gobierno, los alcaldes tenían ya un poder similar, pero sólo para hacer frente a situaciones de emergencia y durante el tiempo estrictamente necesario para lograr el fin perseguido (las llamadas ordenanzas de urgencia o necesidad). La nueva norma permite en cambio adoptar estas ordenanzas para hacer frente a situaciones que no son urgentes y, además, reconociendo a estas ordenanzas carácter estable.

Si bien la violación de estas ordenanzas está castigada con la sanción administrativa prevista en el artículo 7,bis del texto único de los entes locales, se ha previsto que en ciertos casos el municipio pueda acordar modificar la cuantía a pagar en sentido reductivo (apartado quinto) ${ }^{18}$.

Se trata de una competencia de carácter general, prácticamente sin límites, desde el momento en que los conceptos de seguridad física de las personas y seguridad urbana -aunque definidos, como establece la ley, por un decreto ministerial de desarrollo- son susceptibles de afectar a casi todos los aspectos de la vida de las personas, sin límite de ningún tipo ${ }^{19}$. Así, en la práctica, las ordenanzas de los Alcaldes se han ocupado de regular los comportamientos más dispares, multiplicando las obligaciones y prohibiciones de los ciudadanos. Entre lo casos más discutidos se encuentran las ordenanzas que limitan el consumo de bebidas alcohólicas (prohibiéndose la venta a determinadas categorías o en determinados horarios), o aquellas que prohí-

\footnotetext{
16 Cfr. Cons. Stato 885/2001 cit.

17 Art. 54 decreto legislativo 267/2000, según la modificación llevada a cabo por el art. 6 d.l. 23 mayo 2008, n. 92

18 En base al art. 16, 2, ley n. 689/1981 -introducido por el art. 6-bis d.l. 23 mayo 2008, n. 92- «para las vulneraciones de los reglamentos y de las ordenanzas municipales y provinciales, el pleno municipal o provincial, dentro del límite mínimo y máximo de la sanción prevista, puede establcer" el importe del pago reducido, derogando incluso a este fin la regla general.

19 En base al art. 1 d.m. interno 5 agosto 2008 «por seguridad física de las personas se entiende la integridad física de la población y por seguridad urbana un bien público que debe ser tutelado a través de actividades destinadas a la defensa, en el ámbito de los entes locales, del respeto de las normas que regu-
} $70 \quad$ lan la vida civil con el fin de cohesión social”. 
ben comportamientos considerados contrarios a la moral o al decoro urbano (como por ejemplo el estacionamiento de vehículos en zonas frecuentadas por prostitutas, la mendicidad, etc.). Se han llegado a prohibir comportamientos que a juicio de los alcaldes podrían favorecer actos vandálicos o contrarios a la paz pública (por ejemplo el consumo de alimentos en la calle o en lugares públicos). La casuística es amplísima y, como es fácil intuir, cada día se enriquece con nuevas “ocurrentes" prohibiciones. Además, las ordenanzas en ocasiones prevén sanciones accesorias o sustitutivas respecto de las pecuniarias que imponen al sancionado ciertos comportamientos (considerados reeducativos) o prohíben otros (considerados como posibles causas de reincidencias).

De esta forma numerosas conductas han asumido una connotación de ilicitud no porque lo disponga una ley, sino porque así lo han decidido a través de una ordenanza (y por tanto con un acto administrativo) los alcaldes. Es evidente que se trata de una concepción débil del principio de legalidad.

Esta concepción débil del principio de legalidad probablemente es fruto de una incorrecta interpretación, en la medida en que surge de la convicción de que el principio de legalidad aplicable a las sanciones administrativas se funda exclusivamente en el artículo 1 de la ley 689/1981 y no en el artículo 23 de la Constitución. El examen atento de la norma constitucional lleva sin embargo a conclusiones diferentes.

En este sentido hay que señalar que en el pasado la jurisprudencia ha excluido de forma clara que la ley pueda reenviar a la administración la fijación de los límites de la pena a imponer ${ }^{20}$ y, a fortiori, la introducción de otros tipos de sanciones. En verdad, a la luz de las disposiciones constitucionales, la jurisprudencia no ha adoptado una concepción débil del principio de legalidad ni siquiera en lo relativo a la determinación de los comportamientos sancionables. La administración no puede fijar libremente estos comportamientos ${ }^{21}$, los cuales deben estar "suficientemente predeterminados" por la ley y sólo pueden ser "integrados por fuentes reglamentarias delegadas"22. Por otro lado, si bien la reserva de ley del artículo 23 tiene carácter relativo -y permite por tanto una colaboración de las fuentes sublegislativas- la ley no puede limitarse a una mera atribución de poderes a la administración, sino que debe definir al menos los presupuestos subjetivos y objetivos fundamentales de la presta-

20 En particular, Cass., sez. I, 18 enero 2005, n. 936, ha aplicado el «principio... en base al cual debe considerarse en todo caso prohibido que las normas primarias reenvien a las secundarias la definiicón de las sanciones".

21 Según la Cass., sez. I, 27 enero 2005, n. 1696 «las prestaciones obligatorias impuestas coactivamente" deben «ser impuestas en base a una ley", la cual debe establecer «los criterios idóneos para regular eventuales márgenes de discrecionalidad dejados a la administración pública para la determinación de la concreta prestación y, por otra parte, con el finde excluir que la discrecionalidad pueda transformarse en arbitrariedad" debe fijar "directamentela el objeto de la prestación y los criterios para su cuantificación".

22 Cfr. Cass., sez. I, 20 marzo 1998, n. 2937. 
ción impuesta, de forma que limite la discrecionalidad administrativa ${ }^{23}$. También porque en caso contrario resultaría que el mismo sujeto (la administración pública) impone la obligación de pagar cantidades de dinero (o de llevar a cabo prestaciones) y después se beneficia de estos ingresos. Es muy dudosa desde esta perspectiva la legitimidad constitucional de una ley que contenga una delegación en blanco a las ordenanzas de los alcaldes para la regulación de todos o casi todos los aspectos de la vida de las personas.

Esta lectura del principio de legalidad es coherente con la función de la reserva de ley del artículo 23. En este sentido es verdad que el artículo 23 -a diferencia de otras disposiciones constitucionales ${ }^{24}-$ no contiene una explícita referencia de los fines para los que se establece la reserva de ley. Sin embargo, según una tradición jurídica consolidada -que se ha reafirmado en el propio artículo $23^{25}$ - dirigida a garantizar la libertad y la propiedad, no es posible que la administración determine los presupuestos para imponer a las personas el pago de cantidades de dinero o el cumplimiento de prestaciones personales. Justamente este es el fin implícito de la reserva de ley contenida en el artículo 23 de la Constitución, la cual no se respeta cuando la ley se limita simplemente a hacer un reenvio a otras fuentes, según una concepción débil y formal del principio de legalidad.

A todo lo expuesto cabe añadir que las ordenanzas de los alcaldes pueden ampliar el ámbito de los comportamientos ilícitos hasta llegar a afectar a la libertad personal, la cual, según una concepción evolutiva, no sólo hay que tener en cuenta frente a coerciones físicas, sino también en casos de otros tipos de coacciones ${ }^{26}$. Piénsese, para seguir con ejemplos de ordenanzas aprobadas, en la prohibición de reuniones de dos o más personas en algunas zonas de la ciudad. Al margen de toda consideración sobre la oportunidad de este tipo de normas, hay que destacar que los límites a estas libertades están sujetos, como hemos visto, a una reserva absoluta de ley, así como a una reserva de jurisdicción.

23 Cfr. Corte cost. 5 mayo 1998, n. 507 en la que se afirma que "con la finalidad de que los tributos o las pretaciones impuestas con carácter general se sujeten al artículo 23 ” es necesaria que por la ley se indiviualicen algunos elementos: "Ios sujetos obligados a la prestación y el objeto de la misma, los criterios razonables y adecuados para la concreta fijación de la obligación y, por último, el procedimiento a seguir para excluir posibles arbitrariedades por parte de la administración".

24 Se piense, por ejemplo, en el art. 97 Cost., el cual establece que los órganos públicos están organizados mediante leyes "de forma que se garanticen la imparcialidad y el buen funcionamiento de la administración pública".

25 Según Fedele A., Commento all'art. 23 Cost., in AA.VV. (a cura di Branca G.), Commentario alla Costituzione. Rapporti civili (artt. 22-23), Bologna, 1978, pp. 24 y ss., ya antes de la entrada en vigor de la Constitución la reserva de ley contenida en el artículo 30 del Estatuto Albertino con referencia a los tributos se aplicaba a todas las prestaciones coercitivas a favor del Estado, ya que se entendía que su fundamento estaba en la "tutela de la esfera de las libertades individuales de cada un miembro de la sociedad fente a los poderes soberanos del Estado". Según esta lógica, el art.23 Cost. habría codificado un "principio constitucional más general según el cual sólo mediante ley es posible incidir en la esfera de la propiedad y la libertad individual".

26 Corte cost. 7 diciembre 1994, n. 419. 


\section{EL PRINCIPIO DE PERSONALIDAD}

El principio de personalidad está sancionado por el artículo 27 de la Constitución, según el cual "la responsabilidad penal es personal". A esta norma se atribuyen tres significados. En una primera acepción el principio implica que la sanción penal debe castigar sólo a la persona infractora y no a otros sujetos (responsabilidad por hechos propios), ya que la función reeducativa de la pena debe dirigirse justamente al autor de la violación ${ }^{27}$. En una segunda acepción, la sanción debe castigar a un sujeto que haya actuado con conciencia del elemento psicológico previsto por la norma (responsabilidad por hecho doloso o culposo), ya que sólo este sujeto es merecedor de la sanción. Por último, ante la perplejidad de la doctrina, la jurisprudencia constitucional atribuye al principio de personalidad un significado más. La sanción sólo puede castigar a las personas físicas, no a las jurídicas ni por tanto a los entes (responsabilidad de la persona física) ${ }^{28}$.

Como se desprende con claridad de su redacción literal, el artículo 27 se refiere tan sólo a las sanciones penales y no a las sanciones administrativas. También en este caso, sin embargo, al aprobar la disciplina general de las sanciones administrativas y con una lógica de reproducción sustancial del sistema penal, la ley 689/1981 ha incorporado el principio con sus tres significados. De esta forma se ha previsto que en las infracciones castigadas con sanción administrativa "cada uno es responsable de la propia acción u omisión” (artículo 3 de la ley). Por el hecho de hacer referencia a la conciencia y voluntad del hecho (artículo 3), así como a la capacidad de entender y querer ${ }^{29}$ y además a la mayoría de edad (artículo 2), también se deduce que la sanción sólo puede castigar a las personas físicas ${ }^{30}$.

Sin embargo, el principio de personalidad tiene en el caso de las sanciones un fundamento legislativo, con todas las consecuencias que de ello se derivan en relación a la posibilidad de que normas posteriores a la general de 1981 establezcan reglas diversas.

El problema se ha suscitado de forma muy marginal en materia de responsabilidad por hechos propios, ya que las normas posteriores a la ley de 1981 han respetado este principio. La Corte Constitucional fue llamada a pronunciarse sobre esta cuestión en una única ocasión. La Corte declaró inconstitucional una normativa en materia de circulación por carretera en la parte en la que preveía la imposición de una sanción accesoria (la reducción de los puntos del carné de conducir) al propietario del

27 Así lo establece el art. 27, 3, Cost. Precisando que la finalidad de la pena es de tipo reeducativo.

28 Corte cost. 30 diciembre 1998, n. 456.

29 Quien tiene a su cargo la vigilancia del incapz responde por un hecho propio (que consiste en la falta de vigilancia) - por lo tanto con pleno respecto del princpio de personalidad, y a salvo de que demuestre que no pudo impedir el hecho. No se trata por tanto de una responsabilidad objetiva o por hecho de un tercero. El caso típico es el de los padres que responden de la infracción cometida por el hijo menor de edad.Los padres pueden evitar esta responsabilidad únicamente si demuestran que no pudieron impedir el hecho cometido.

30 Cass.,sez. trib., 25 mayo 2007, n. 12264. 
vehículo, aún si el mismo no había sido el autor de la infracción ${ }^{31}$. La declaración de inconstitucionalidad no se basó, sin embargo, en el artículo 27 de la Constitución, sino en la irrazonable diversidad de esta regla específica en relación con lo dispuesto en la ley general 681/1981. La Corte ha destacado la violación del principio de igualdad sancionado en el artículo 3 de la Constitución en la medida en que el artículo 3 de la ley $681 / 1981$ "vincula la responsabilidad por los comportamientos tipificados en la norma al carácter personal de la conducta activa u omisiva del infractor"32, excluyendo por tanto la aplicación de sanciones a sujetos diversos del infractor.

Según esta acepción el principio de personalidad implica también que, cuando la infracción se haya cometido en concurso por varios sujetos, la pena prevista se impondrá a cada uno de ellos. Precisamente porque la sanción no mira a la reparación del daño material, sino que consiste en una pena, no encuentra aplicación la regla civil sobre el resarcimiento según la cual, en presencia de muchos autores del daño, la medida del resarcimiento no varía (artículo 2055 del código civil). Rige, en cambio, la regla diferente según la cual cada uno de los concurrentes debe ser castigado con la sanción prevista por la infracción (artículo 5 de la ley 689/1981).

Esta acepción del principio no queda contradicha por la previsión de que, en garantía del pago de la sanción, se pueda prever la implicación de otros sujetos diversos del autor material de la infracción. En efecto, el artículo 6 de la ley 689/1981 establece que algunos sujetos pueden ser obligados al pago de la suma debida a título de sanción de forma solidaria con el autor de la infracción ${ }^{33}$. Sin embargo, el obligado solidario no es el destinatario "último" de la sanción, ya que si paga tiene acción de regreso frente al autor de la infracción. Hasta el punto de que si el autor de la infracción fallece, la obligación de pagar la infracción no sólo se extingue en relación a los herederos (como expresamente establece el artículo 7 de la ley 689/1981), sino también en relación de los obligados solidarios, en tanto ya no podrán ejercitar la acción de regreso ${ }^{34}$.

Las infracciones administrativas también deben caracterizarse por la subsistencia del elemento psicológico (indiferentemente doloso o culposo, si bien no está en absoluto excluida la posibilidad de ilícitos sólo dolosos) ${ }^{35}$. Sin embargo, mientras que del artículo 27 se desprende que en el caso de las sanciones penales la carga de la

31 Corte cost. 24 enero 2005, n. 27.

32 Corte cost. 27/2005 cit.

33 Se trata de los siguientes sujetos: a) el proprietario del bien que sirvió o fue destinado para cometer la infracción (o bien el usufructurario o, si se trata de bienes inmuebles, el titular del derecho personal de disfrute); b) la persona provista de autoridad o encargada de la dirección en el caso de infracción cometida por persona con capacidad de entender y querer pero sujeta a la autoridad, dirección o vigilancia de tercero c) el empresario o la entidad por la infracción cometida por el empleado o por el representante legal en el ejercicio de sus funciones o cometidos. Por otra parte estos sujetos no deben responder de las obligaciones si prueben no haber podido impedir el hecho (esta prueba liberatoria no ha sido aun admitida para las personas jurídicas, los entes o empresarios respecto de los actos del empleado o del representante).

$74 \quad 34$ Cass., III, 6 marzo 2000, n. 2501. 
prueba del elemento psicológico corresponde al ministerio fiscal ${ }^{36}$, la jurisprudencia ha interpretado la indiferencia del artículo 3 de la ley 681/1981 respecto del carácter doloso o culposo de la infracción en el sentido de una presunción de culpabilidad con referencia al imputado. Se trata de una presunción iuris tantum, que comporta en todo caso la inversión de la carga de la prueba ${ }^{37}$. En otras palabras, debe ser el interesado el que demuestre haber actuado sin la concurrencia del elemento psicológico.

Como se ha dicho, del conjunto de las disposiciones contenidas en el título I de la ley 681/1981 (en particular en los artículos 2,3 y 7) la jurisprudencia ha deducido que el autor de un ilícito administrativo sólo puede ser una persona física, con exclusión de entidades como sociedades o entes en general (incapaces por si mismos de realizar una conducta consciente y voluntaria). La circunstancia de que la persona física haya actuado como órgano o representante de una persona jurídica sólo importa a los efectos diversos de la responsabilidad solidaria de ésta última (artículo 6 de la ley $681 / 1981)^{38}$, lo que, como se ha dicho, no supone una equiparación de la posición del responsable solidario con la del autor de la infracción.

Tampoco esta última concepción del principio tiene un fundamento constitucional. No existe por tanto ninguna preclusión a la posibilidad de que por leyes posteriores a la ley 689/1981 se introduzcan formas de responsabilidad del ente autor de la infracción. Por esta razón en la reciente legislación son cada vez más numerosas las hipótesis de responsabilidad directa de la empresa por infracciones administrativas, especialmente en la regulación de actividades económicas en las que el papel de la empresa es central (por ejemplo defensa de la competencia, sector energético, actividad crediticia, telecomunicaciones, obras públicas, ayudas comunitarias en el sector agrícola, etc.).

Un caso peculiar es el decreto legislativo de 8 de junio de 2001, número 231, que ha introducido la "responsabilidad de los entes por las infracciones administrativas vinculadas a un delito" (artículo 1, 1). En base a esta regulación, el ente -entendido en un sentido muy amplio (artículo 1, 2 y 3 ) queda sujeto de forma directa (es decir por acto propio) a múltiples tipologías de sanciones (pecuniarias y de prohibición) cuando las personas que tienen la representación o la gestión, o incluso los dependientes de tales personas, cometan algún tipo de delito en interés o ventaja del ente ${ }^{39}$. La aplicación de estas sanciones se solicita al juez penal competente para conocer de los delitos a los que se vinculan las infracciones del ente. El procedimiento es análogo al que se sigue para la comprobación de los delitos (artículo 36, 1 y 2), si bien con notables singularidades. Así el archivo de las actuaciones puede ser acordado por el ministerio público (artículo 58).

La responsabilidad de los entes suscita nuevos problemas interpretativos, en particular, el relativo al destino de la sanción en caso de sucesión entre personas jurí-

36 La imposición de una sanción penal presupone la demostración de la culpabilidad del autor de la infracción, sin ninguna presunción para otdo tipo de delito (cfr. Cass. pen., sez. III, 15 abril 1997, n. 4511).

37 Cfr. In fine Cass.,sez. II, 10 febrero 2009, n. 3251.

38 Cass., sez. lav., 28 ljulio 2000, n. 9975.

39 Se trata de delitos contenidos en los artt. 24 y ss. decreto legislativo 231/2001. 
dicas. Para las infracciones administrativas vinculadas a un delito la cuestión está específicamente regulada en los artículos 28 y siguientes del dl 231/2001, preceptos que sustancialmente mantienen firme la responsabilidad para el nuevo ente en caso de actuaciones modificativas (transformación, fusión, escisión y cesión de empresa) y la extienden al ente sucesor en caso de cesión de empresa. El problema es más complejo -y no ha encontrado aún una solución definitiva en la jurisprudencia- en el caso de otras sanciones administrativas, en relación a las cuales nada se ha establecido y la solución se ha dejado a la jurisprudencia. En base a una decisión muy citada de la Corte de Justicia en materia de protección de la competencia ${ }^{40}$, la doctrina jurisprudencial aplicable supone que la sociedad que suceda jurídicamente a otra sociedad disuelta, continuando con sus actividades económicas, es sancionable por las conductas realizadas por la anterior en virtud del criterio de la "continuidad económica"

Más recientemente, el Consejo de Estado ha planteado una cuestión de interpretación prejudicial ante la Corte de Justicia en relación a otro aspecto del problema. Ha preguntado si para la individualización del sujeto sancionable corresponde al Tribunal de defensa de la competencia (Autorità garante per la concorrenza e il mercato) la función de "valorar discrecionalmente la concurrencia de circunstancias que justifiquen la imputación al sucesor económico de la responsabilidad por infracciones en materia de concurrencia cometidas por la persona jurídica de la que pasa a formar parte, aun cuando ésta no haya dejado de existir en el momento de la decisión, con el fin de que el efecto útil de las normas sobre la competencia no resulte perjudicado por las modificaciones llevadas a cabo en la forma jurídica de la empresa" (en el caso concreto se trataba de una sociedad de capital público a la que sucede un ente público económico ${ }^{42}$. La Corte de Justicia resolvió la cuestión afirmando el principio según el cual "los artículos 81 y siguientes del Tratado deben ser interpretados en el sentido de que, en caso de entes dependientes de la misma autoridad pública, siempre que una conducta constitutiva de una misma infracción a las reglas de la competencia sea cometida por un ente y posteriormente continuada hasta su fin por otro ente sucesor del primero, el cual no ha dejado de existir, el segundo ente puede ser sancionado por la infracción en su totalidad, si se prueba que estos dos entes han permanecido bajo la tutela de la misma Autoridad"43.

\section{EL PROCEDIMIENTO SANCIONADOR}

\section{El justo procedimiento y la relación con la regulación general del procedimiento administrativo}

Como se ha señalado con anterioridad, la aplicación de las sanciones administrativas no requiere la previa tramitación de un proceso. Esto no quiere decir que la acti-

40 Corte giust. 28 marzo 1984, cause riunite C-29/83 e 30183.

41 Cons. Stato, sez. VI, 16 marzo 2006, n. 1397.

42 Cons. Stato, sez. VI, 11 abril 2006, n. 1998.

43 Corte giust., pleno, 11 diciembre 2007, C-280/06. 
vidad dirigida a la aplicación de las sanciones no deba estar procedimentalizada. De hecho, el principio general de "justo procedimiento" -que deriva del artículo 97 de la Constitución (en particular de los cánones de imparcialidad y del buen funcionamiento de la administración)- requiere siempre que "el destinatario del acto debe ser informado del inicio del procedimiento, tener la posibilidad de intervenir en defensa propia, obtener una resolución motivada y poder recurrir ante un juez"44.

La ley 689/1981 contiene una detallada disciplina procedimental de estas garantías que la jurisprudencia ha tenido ocasión de examinar también en relación con la normativa general sobre el procedimiento contenida en la ley de 7 de agosto de 1990, número 241.

Tras algunas discrepancias jurisprudenciales, la Casación en sección única ha fijado doctrina recientemente en el sentido de que la ley 689/1981 tiene una relación de especialidad con respecto a la ley $241 / 1990$, la cual por tanto no es de aplicación en los procedimientos para la imposición de sanciones administrativas. En la misma decisión la Casación ha afirmado además que "las disposiciones de la ley 689/1981 constituyen un sistema orgánico y completo, en el que no procede incorporar preceptos externos" (en particular de la regulación de la ley 241/1990) ${ }^{45}$. Por otra parte, la jurisprudencia ha afirmado incluso que las garantías de la ley 689/1991 son "de nivel no inferior" al asegurado por la ley $241 / 1990^{46}$ y satisfacen por tanto de forma plena el principio del justo procedimiento (es más, como veremos, contienen incluso la regulación de mecanismos de garantía -como la audiencia personal- que no están previstos en la disciplina general del procedimiento administrativo).

\section{El procedimiento sancionador en la ley $689 / 1981$}

El procedimiento sancionador se inicia con la actividad de comprobación de los ilícitos administrativos. Esta actividad tan sólo puede ser llevada a cabo por sujetos cualificados: se trata preferentemente de los oficiales y los agentes de la policía judicial, los cuales pueden apreciar la existencia de toda la tipología de ilícitos administrativos (artículo 13 de la ley 689/1981). En ocasiones la ley individualiza otras categorías de agentes que pueden apreciar ilícitos en sectores concretos. En estos casos la atribución de la competencia de apreciación es de “estricta interpretación” y los actos de apreciación, redactados por estos sujetos en relación a ilícitos que no forman parte de su competencia, no pueden fundamentar conforme a derecho una resolución sancionadora ${ }^{47}$.

Los actos destinados a la comprobación están enumerados en la ley 681/1981 de forma muy genérica, lo que permite incluir -junto a la asunción de información- cual-

44 Corte cost. 23 marzo 2007, n. 104.

45 Cass., sez. un., 27 abril 2006, n. 9591.

46 Cass., sez. lav., 15 diciembre 2005, n. 27681

47 Cass., sez. un., 9 marzo 2009, n. 5621. 
quier tipología de actuación inspectora o técnica. No se admiten sin embargo los actos que inciden sobre derechos inviolables como la libertad personal o el domicilio (sujetos por los artículos 13 y siguientes de la Constitución a reserva de jurisdicción). De hecho este límite no afecta tan sólo a la aplicación de la sanción sino también a la actividad de comprobación ${ }^{48}$. Son por tanto inutilizables los resultados de una actuación de comprobación efectuada en el domicilio (debiéndose entender por tal no sólo la habitación, sino también cualquier otro lugar "destinado permanentemente o transitoriamente al desarrollo de la vida privada o la actividad laboral”49).

El agente instructor redacta un acta sobre la actividad de comprobación y sus resultados. Según la jurisprudencia, algunas afirmaciones del acta tienen fuerza de fe pública de conformidad con el artículo 2699 y 2700 del código civil, y por tanto sólo pueden ser contradichas mediante un trámite incidental destinado a declarar la falsedad de estas afirmaciones (demanda de falsedad). En particular el acta adquiere este valor en relación a la descripción de los hechos que el agente instructor ha llevado a cabo, así como de los hechos que ha podido conocer sin margen de discusión (como por ejemplo la lectura de un número de matrícula de un vehículo parado). No están cubiertos con la fe pública los contenidos del acta no verificables y controlables mediante procedimientos objetivos con respecto a la fuente por la que se obtuvo la información, como por ejemplo los actos que se produjeron de forma repentina (como la lectura de una matrícula de un vehículo que atraviesa un cruce $^{50}$. La jurisprudencia ha llegado a una solución diversa con relación al control del uso del cinturón de seguridad por parte del conductor de un vehículo en movimiento ${ }^{51}$ ). Con mayor motivo, no están cubiertas por la fe pública las valoraciones técnicas del agente instructor ${ }^{52}$.

Una vez acreditada, la infracción debe ser notificada a los interesados, es decir, a los autores de la infracción y a los eventuales responsables solidarios (artículo 14 de la ley 681/1981). De este modo se les permite ejercitar las acciones en defensa de sus derechos $^{53}$ y eventualmente efectuar el pago reducido. La notificación debe producirse de forma inmediata, en la medida de lo posible. Sin embargo la falta de una notificación inmediata no afecta a la validez de la resolución sancionadora si se procede a notificar el contenido de la infracción dentro del plazo de caducidad establecido en la misma norma ${ }^{54}$. Sólo en algunos procedimientos sancionadores especiales la falta injustificada de una notificación inmediata comporta la invalidez del acto de aplicación de la sanción. Así está previsto en el caso de las sanciones por infracciones de tráfico ${ }^{55}$.

48 En base a lo establecido en el artículo 14 de la Constitución, esta prohibición no es válida para las comprobaciones en determinadas materias, como la tributaria o sanitaria.

49 Cass., sez. I, 27 enero 2005, n. 1699.

50 Cass., sez. I, 30 diciembre 2005, n. 28939.

51 Cass., sez. un., 24 julio 2009, n. 17355.

52 Cass., sez. III, 25 febrero 2002, n. 2734.

53 Cass., sez. I, 17 febrero 2006, n. 3536; sez. II, 8 febrero 2006, n. 2817.

54 Cass., sez. I, 7 abril 2005, n. 7319.

55 Cfr. los artt. 200 e 201 decreto legislativo 30 abril 1992, n. 285 (codigo de la circulación). En el código de circulación se recogen normativamente algunas hipótesis de exclusión de la obligación de noti- 
En todo caso, cuando no sea posible u obligatorio proceder de forma inmediata a la notificación, ésta debe llevarse a cabo en el plazo de caducidad de 90 días (aunque a menudo las regulaciones sectoriales prevén términos más amplios). El plazo empieza a correr desde el momento de la constancia de la comisión de la infracción, es decir, desde el "pleno conocimiento de la conducta ilícita" ("lo que a su vez determina la fijación, también a efectos de una correcta formulación de la contestación, de la existencia y de la consistencia de la infracción y sus efectos" ${ }^{56}$ ). En este caso, "la simple constatación de los hechos en su materialidad no coincide necesariamente con su fijación”, sobre todo "si tiene lugar una posterior actividad instructora y valorativa" 57.

Dentro del plazo de sesenta días desde la imputación los interesados pueden poner fin al procedimiento sancionador mediante la conciliación a través del pago de una cantidad de dinero equivalente al doble del mínimo, o en caso más favorable, a la tercera parte del máximo (artículo 16 de la ley 689/1981). El pago no tiene valor de admisión de la responsabilidad, pero la jurisprudencia de la Casación y de la Corte Constitucional afirma que a través del pago "el interesado manifiesta la voluntad de prestar conformidad a la imputación de responsabilidad por la infracción en cuestión” ${ }^{58}$.

Si los interesados no efectúan el pago en cuantía reducida, el acta se eleva al órgano competente para acordar la imposición de la sanción (artículo 17 de la ley 681/1981). Después de las reformas sobre la organización de las administraciones públicas de los años 90 y la afirmación de la distinción entre política y gestión esta competencia pertenece por lo general a los órganos burocráticos y no a los políticos (así, por ejemplo, en los municipios a los funcionarios directivos y no al alcalde) ${ }^{59}$. El órgano competente debe decidir teniendo en cuenta no sólo el contenido del acta, sino también el punto de vista de los interesados. Estos pueden, por tanto, incorporar dentro de los treinta días de la comunicación memorias y documentos y pueden también solicitar ser oídos. La administración debe garantizar el ejercicio de estas facultades. Por tanto, la falta de audiencia del interesado que la hubiera solicitado vicia de ilegalidad el posterior acto sancionador que se pueda dictar al término del procedimiento ${ }^{60}$.

La administración debe decidir sobre la existencia de la infracción comunicada, lo que debe hacerse respetando una cierta vinculación: el infractor no podrá ser sancionado por otro hecho o por un tipo infractor diverso del que resulte del acuerdo de imputación. Esta necesaria correspondencia no vincula tan sólo a la administración que puede imponer la sanción ${ }^{61}$, ya que también vincula al juez en caso de un eventual

\footnotetext{
ficación inmedata (art. 201, comma 1-bis): la jurisprudencia, sin embargo, ha precisado que no basta con una mera reproducción en el acta de la hipótesis normativa sin una "referencia, aunque sea sumaria, a las circunstancias de tiempo, lugar y de hecho que hicieron imposible la notificación inmediata por parte de los agentes que redactaron el acta" (Cass., sez. II, 28 abril 2005, n. 8837).

56 Cons. Stato, sez. VI, 30 enero 2007, n. 341.

57 Cass., sez. un., 9 marzo 2007, n. 5395.

58 Corte cost., ord. 20 febrero 2007, n. 46.

59 Cass., sez. II, 8 abril 2009, n. 8560.

60 Cass., sez. I, 24 julio 2004, n. 13505.

61 Cass., sez. I, 8 septiembre 1999, n. 9528.
} 
juicio de impugnación del acto sancionador (en este sentido el juez no podrá castigar una infracción diversa de la que sancionó la administración) ${ }^{62}$.

La decisión debe ser motivada, debiendo también tener en cuenta lo alegado por el interesado. La jurisprudencia sostiene sin embargo que no es necesaria una motivación analítica y detallada como la que es exigible a una resolución judicial. Basta con dar cuenta de los fundamentos de hecho de las decisiones -también deducibles per relationem del acta de comprobación- y del examen llevado a cabo de los argumentos formulados por los interesados en su defensa ${ }^{63}$.

El procedimiento sancionador concluye con una resolución que impone el pago de la sanción (resolución de condena) o bien con un pronunciamiento de archivo. En la resolución de condena la sanción pecuniaria se cuantifica dentro de los límites establecidos por la ley de acuerdo con los criterios fijados en el artículo 11 de la ley $689 / 1981^{64}$. Se trata de criterios centrados en la personalidad del infractor y sobre los caracteres de la infracción, no sobre el interés lesionado o sobre el daño ocasionado, en la medida en que la sanción no tiene función reparatoria.

\section{LAS DISCIPLINAS ESPECIALES: EN PARTICULAR, LA LEGISLACIÓN REGIONAL}

Lo dispuesto en la ley 681/1981, precisamente porque se contiene en una ley ordinaria, puede ser derogado por leyes posteriores. La jurisprudencia exige por lo general que estas derogaciones tengan carácter expreso ${ }^{65}$.

Problema distinto es el relativo a la admisibilidad y a la extensión de estas derogaciones. Sobre esta cuestión incide el reparto de competencias legislativas entre el Estado y las Regiones, regulado principalmente (pero no exclusivamente) por el artículo 117 de la Constitución (según la redacción dada por la ley constitucional de 18 de octubre de 2001, número 3).

Las derogaciones a la ley 689/1981 no plantean especiales problemas cuando las regulaciones sectoriales se llevan a cabo por la legislación estatal. De hecho en estos casos las normas especiales pueden modificar la regulación general, procedimental y

62 Cass., sez. II, 14 abril 2009, n. 8892.

63 Cass., sez. II, 13 abril 2006, n. 8649.

64 Según el Cons. Stato, sez. VI, 2 agosto 2004, n. 5368, estos criterios también son de aplicación en las sanciones de prohibición establecidas por el legislador dentro de los límites mínimo y máximo o en los casos de sanciones pecuniarias cuantificadas por referencia a una porcentual variable de una determinada importancia. En particular, las sanciones en materia de defensa de la competencia que pueden llegar "hasta" una cierta proporción de lo facturado por la empresa (art. 15, legge n. 10 octubre 1990, n. 287)- se cuantificarán de forma concreta "en relación con todos los parámetros previstos por el art. 11 de la ley $\mathrm{n}$. $689 / 1981$, incluidas las condiciones económicas (que
65 Cons. Stato, sez. VI, 10 enero 2007, n. 26. 
procesal con el único infranqueable límite de la salvaguardia de las garantías establecidas por las disposiciones constitucionales (artículos 23, 97 y 24 de la Constitución). Así, por ejemplo, algunas reglas especiales establecen un plazo para la imputación diverso del establecido por el artículo 14 de la ley 681/198166. En algunos casos se excluye la facultad de pagar de forma reducida ${ }^{67}$.

En otros casos el procedimiento adquiere características totalmente diversas del procedimiento común. Por vulneraciones del código de tráfico está previsto un plazo preclusivo para la tramitación del procedimiento sancionador ${ }^{68}$ (mientras que en el régimen general el único plazo que debe respetarse para la conclusión del procedimiento es el de la prescripción de la infracción, plazo fijado en cinco años por el artículo 28 de la ley 681/1981) ${ }^{69}$. Para estas mismas infracciones ${ }^{70}$, como para las tributarias $^{71}$, el acto de imputación puede, en determinadas circunstancias, tener por si mismo eficacia de título ejecutivo sin necesidad de la emanación de un posterior acto sancionador. Por esta razón, en estos casos el acto de imputación es inmediatamente impugnable en sede administrativa o jurisdiccional.

El razonamiento es mas complejo cuando se debe abordar la relación entre la ley $681 / 1981$ y las leyes regionales, particularmente después de la reforma introducida por la ley constitucional 3/2001. Las normas regionales también deben asegurar de forma plena el respeto de las garantías constitucionales (artículos 23,24 y 97). Pero más allá de estos límites las Regiones pueden regular el ejercicio de la potestad sancionadora en las materias que sean de su competencia legislativa, ya que la competencia sancionadora no es una materia en si misma sino accesoria a otras materias sobre las que se posea potestad legislativa ${ }^{72}$. Obviamente la extensión de la potestad legislativa regional varía según que estemos ante competencias regionales residuales-exclusivas o concurrentes.

En el primer caso "la diversificación de las leyes regionales en supuestos de materias pertenecientes a la competencia residual de las Regiones no sólo no está en contradicción con la Constitución, sino que es una consecuencia natural de sus propias reglas"73. En cambio, en las materias de legislación concurrente las Regiones están vinculadas por los principios establecidos en la legislación estatal, incluyendo aquellos que puedan deducirse de la ley 681/1981. Por ejemplo, las Regiones

66 Por ejemplo, el art. 4 ley n. 23 diciembre 1986, n. 898 -en materia de ayudas comunitarias en el sector agrícola- establece un plazo de 180 días; el art. 201, 1, decreto legislativo 285/1992 -en materia de tráfico-establece un plazo de 150 días..

67 Cfr. l'art. 135, 4, decreto legislativo 152/2006 en materia di protección de las aguas; el art. 4, 1, lett. b, ley n. 898/1986 para las ayudas comunitarias en el sector agrícola así como numerosas normas sobre las sanciones impuestas por las autoridades administrativas independientes.

68 Cass., sez. II, 13 abril 2006, n. 8652.

69 Cass. 9591/2006 cit.

70 Cfr. l'art. 203, 3, decreto legislativo 285/1992.

71 Cfr. l'art. 16, 4, decreto legislativo 18 diciembre 1997, n. 472.

72 Corte cost. 13 enero 2004, n. 12.

73 Corte cost. 11 mayo 2006, n. 199. 
no pueden modificar la determinación de los órganos territorialmente competentes para imponer las sanciones ${ }^{74}$, ni derogar el principio de legalidad estricta75, mientras que si puede escoger entre prever sanciones fijas o graduables entre un máximo y un mínimo ${ }^{76}$.

Recientemente, sin embargo, se observa la tendencia a reconocer al legislador estatal la potestad de normar la materia sancionadora de forma muy detallada en las materias sobre las que posee una competencia concurrente en razón de una finalidad de regulación unitaria (por ejemplo en los casos que se trata de materias vinculadas al cumplimiento de obligaciones comunitarias) ${ }^{77}$. En concreto, en los casos de sanciones por la prohibición de fumar en locales públicos, la Corte constitucional ha afirmado que "la naturaleza del principio fundamental de prohibición de humo, y la correlativa competencia estatal para individualizar ya sea los presupuestos de hecho del ilícito administrativo ya sea el alcance de las sanciones correspondientes, inciden inevitablemente en la regulación del procedimiento administrativo establecido para acreditar la comisión de la infracción y determinar la sanción a imponer". Se incluyen de este modo entre los "principios fundamentales", reservados al legislador estatal, no sólo "las normas que determinan los supuestos de hecho del ilícito" y "las relativas a las sanciones", sino también la regulación del "procedimiento destinado a su aplicación"78.

Otro límite significativo a la potestad legislativa de las Regiones puede derivar de la reserva al Estado de la potestad en materia de "ordenamiento penal" (artículo 117,2, letra I de la Constitución). Sin embargo, la ley penal (que siempre es estatal) sólo puede afectar legítimamente en las materias de competencia regional si no impide la aplicación de las sanciones administrativas regionales ${ }^{79}$. Se trata, por otra parte, de una solución ya elaborada por la jurisprudencia de la Casación aplicando el artículo 9,2 de la ley 681/198180. La aplicación de la regla sancionadora regional no se excluye a pesar de que pueda referirse al mismo hecho sancionador que la norma penal, pues en caso contrario el Estado (único competente para establecer la normativa penal) podría invadir siempre las materias de competencia regional. Por otra parte la ley regional podría a su vez obviar el problema estableciendo que la sanción administrativa se aplica de forma conjunta con la sanción penal (acumulación de sanciones) $)^{81}$.

74 Corte cost. 14 octubre 1993, n. 375.

75 Cass. $1696 / 2005$ cit.

76 Corte cost. 28 marzo 2004, n. 159.

77 Corte cost. 17 marzo 2006, n. 106.

78 Corte cost. 16 febrero 2006, n. 63.

79 Corte cost. 5 mayo 2006, n. 183.

80 En base al art. 9, 2, I. 689/1981 no se aplica el principio de especialidad "cuando un mismo hecho está castigado por una norma penal y una norma regional o de las provincias autónomas... que establezca una sanción administrativa". En estos casos"se aplica en todo caso la norma penal, salvo que la misma sólo sea aplicable en defecto de otras normas penales".

81 Cass., sez. III, 13 abril 2000, n. 4792. 
Por último está en todo caso prohibido a las Regiones intervenir en aspectos relativos a la tutela jurisdiccional, reservada al legislador estatal (artículo 117,2, letra I de la Constitución) y regulada por tanto de forma uniforme.

\section{LA TUTELA JURISDICCIONAL}

Aunque el proceso tenga carácter eventual y no sea necesario para la aplicación de las sanciones administrativas, la posibilidad de acudir al juez frente a actos sancionadores representa una lógica consecuencia de los principios constitucionales sobre la irrenunciabilidad de la tutela jurisdiccional, en particular frente a los actos de las administraciones públicas (artículos 24 y 113 de la Constitución).

En la medida en que afecta a un derecho subjetivo la tutela judicial se pide ante el juez ordinario de acuerdo con las reglas generales de distribución de competencias jurisdiccionales, lo que supone acudir al Juez de paz o al Tribunal del lugar donde se ha cometido la infracción. No obstante en ocasiones es competente el juez administrativo, en la medida en que afectan a materias de competencia exclusiva en las que este juez conoce también de derechos subjetivos. Se trata principalmente de sanciones administrativas impuestas por autoridades independientes ${ }^{82}$. También en algunos casos el conocimiento de la infracción administrativa se atribuye el juez penal, al que corresponde también la ejecución de la sanción administrativa. Así en los casos en los que la determinación de la infracción administrativa es prejudicial respecto a la determinación de la infracción penal (artículos 24 de la ley 689/1981).

El juicio de oposición a la sanción administrativa está regulado en los artículos 22 y siguientes de la ley 689/1981. Se trata de un juicio con fuertes connotaciones de especialidad que se inicia por los interesados mediante la interposición de su recurso. El juez, en dicho proceso, podrá disponer de oficio la realización de pruebas ${ }^{83}$ dentro del límite del objeto del recurso, que vendrá fijado por los motivos y las alegaciones de las partes ${ }^{84}$. El hecho de que el objeto del proceso se defina en el momento de interponer el recurso impide al juez, salvo en casos de especial gravedad ${ }^{85}$, anular o reducir la sanción en base a nuevos motivos no expuestos en el recurso. Con mayor motivo, cuando el juez aprecie la inexistencia del tipo propuesto no podrá aplicar una sanción correspondiente a otro tipo que haya podido apreciar durante el proceso ${ }^{86}$.

82 Cfr. El art. 2, 25, ley n. 14 noviembre 1995, n. 481 y el art. 1, 26, ley n. 31 julio 1997, n. 249 para las autoridades de regulación, el art. 33 ley n. 287/1990 para la la Autoridad de defensa de la competencia, el art. 326, 7, decreto legislativo 7 septiembre 2005, n. 209 para el Instituto de vigilancia de las aseguradoras privadas y el art.. 244, 2, decreto legislativo 12 abril 2006, n. 163 para la Autoridad de vigilancia de las obras públicas.

83 Cass., sez. lav., 29 noviembre 2005, n. 25945

84 Cass., sez. I, 24 febrero 2006, n. 4252

85 Según la Cass., sez. II, 25 junio de 2008, n. 17403, el juez puede apreciar de oficio la falta de una base legal de la sanción.

86 Cass. 8892/2009 cit. 
El recurso se interpone normalmente frente al acuerdo de imponer la sanción dictado al amparo del artículo 18 de la ley 689/1981. Por el contrario no es impugnable el acta de apertura del procedimiento, ya que no conlleva la aplicación de la sanción y tan sólo constituye el primer acto de un procedimiento que puede cerrarse con la imposición de la sanción o con su archivo. Como excepción a esta regla cabe mencionar el acta de inicio del expediente en materia de circulación ${ }^{87}$ o los actos de comprobación de las infracciones tributarias en la medida en que, como vimos, son susceptibles de tener efectos de inmediata ejecutividad. El recurso también se puede interponer contra el acto de inicio el expediente de recuperación coactiva de cantidades (la llamada "providencia de exacción ejecutiva"), pero sólo en los casos en los que debido a la falta de notificación de la providencia de ejecución o del acta de instrucción en materia de infracciones de tráfico el interesado se haya visto privado de la tutela judicial frente a dichos actos, la cual se recupera de esta forma en esta fase ${ }^{88}$.

En base al artículo 23 de la ley 689/1981 el juez ordinario puede llevar a cabo un control muy amplio sobre los actos sancionadores, no obstante el juicio tenga como objeto un acto de la administración. Dentro de los límites fijados por el objeto del recurso el juez puede controlar no sólo la validez formal del acto, sino también la concurrencia de los presupuestos de hecho y de derecho de la infracción ${ }^{89}$. El juez, en otras palabras, lleva a cabo un examen "de la concurrencia de los presupuestos de hecho y de derecho con respecto a la infracción impugnada, de forma que el objeto del recurso no es la sanción sino la relación sancionadora" 90 . Por otra parte, como ocurre siempre en los juicios ordinarios en que es parte la administración pública, el control sobre los hechos no sufre límites especiales por razón de las apreciaciones técnicas que se hayan podido realizar en sede administrativa91. El único límite que puede aplicarse al control judicial deriva del contenido del acta, dado que los hechos en ella recogidos dan prueba de los hechos salvo que se plantee una querella por falsedad. Se trata, no obstante, de un límite relativo, ya sea porque frente al valor del acta el oponente puede oponer la verdad de los hechos recogidos en el acta mediante la presentación de una querella por falsedad, ya sea porque, como hemos dicho, el límite no afecta a "los juicios de valoración" del contenido del acta (que pueden ser contestados con los medios ordinarios de prueba) ${ }^{92}$.

También los poderes decisorios son muy amplios. El juez puede anular, parcial o íntegramente, el acto sancionador o bien modificarlo, por ejemplo reduciendo la sanción impuesta.

Cuando el recurso se tramita ante el juez administrativo, en los casos de jurisdicción exclusiva, los poderes decisorios son análogos a los del juez ordinario. De hecho, mientras en un primer momento se había excluido in toto la aplicabilidad del artículo

87 Corte cost. 7 mayo 2002, n. 160.

88 Cass., sez. I, 20 abril 2006, n. 9180.

89 Cass., sez. II, 11 enero 2006, n. 217

90 Cass., sez. I, 27 febrero 2006, n. 4302.

91 Cass., sez. I, 16 mayo 2006, n. 11479.

92 Cass., sez. I, 30 diciembre 2005, n. 28939. 
23 de la ley 681/1981 en razón de la singularidad del proceso contencioso-administrativo ${ }^{93}$, posteriormente la jurisprudencia ha afirmado que el juez administrativo debe tener los mismos poderes que el juez ordinario atendiendo a la identidad de las posiciones subjetivas tuteladas (derecho subjetivo) ${ }^{94}$.

Esta equiparación afecta en verdad sólo a los poderes decisores (de anulación y de modificación de la entidad de la sanción) ${ }^{95}$, ya que es mucho más discutido que pueda alcanzar también a la extensión del control ${ }^{96}$. El problema se ha planteado de forma particular en relación a las valoraciones técnicas efectuadas por la administración. En el pasado el juez administrativo había afirmado que las valoraciones técnicas llevadas a cabo por la administración no podían ser sustituidas por las que pudiera llevar a cabo el juez (control débil)97. Posteriormente, en razón de las críticas doctrinales, el Consejo de Estado ha precisado el concepto de "control débil" estableciendo que "con está expresión se ha tratado tan sólo de poner un límite a la decisión del juez, el cual, una vez se han acreditado de forma completa los hechos y se ha verificado el proceso de valoración llevado a cabo por la Autoridad (de defensa de la competencia) en base a reglas técnicas, que también se han controlado, si entonces el juez estima las valoraciones de la Autoridad correctas, razonables, proporcionales y aceptables, no debe ir más allá hasta llegar a formular decisiones propias autónomas, ya que en este caso asumiría él la titularidad del poder sancionador" 98 . Por último, la jurisprudencia administrativa ha dado un paso más con el fin de imponer una mayor coherencia del sistema en su conjunto, un sistema que no admite un control diferente sobre actos totalmente idénticos desde el punto de vista sustancial sólo por el hecho de que la demanda se presente ante un juez $u$ otro (ordinario o administrativo). En este sentido el Consejo de Estado ha afirmado que el control sobre los actos sancionadores tiene carácter de plenitud y, por tanto, el juez administrativo debe poder "ya sea reexaminar las decisiones técnicas llevadas a cabo por la administración, ya sea aplicar la interpretación correcta a los conceptos jurídicos indeterminados que configuran el tipo infractor”. Únicamente

93 Cass., sez. un., 5 enero 1994, n. 52.

94 Cons. Stato, sez. VI, 2 agosto 2004, n. 5368. El Consejo de Estado, por su parte, destaca que cuando las sanciones administrativas en materia de defensa de la competencia sean impuestas por la Comisión, los poderes decisorios de la Corte de Justicia no tiene límite (sobre los poderes de la Corte de Justicia en los procesos sobre los actos de la Comisión en materia de defensa de la competnecia cfr. l'art. 31 reg. CE 16 dicembre 2002, n. 1/2003).

95 Cfr. Cons. Stato, sez. VI, 27 febrero 2008, n. 695; en el mismo sentido, Cons. Stato, sez. VI, 23 abril 2002, n. 2199; Cons. Stato, sez. VI, 30 agosto 2002, n. 4362.

96 Cass., sez. un., 29 abril 2005, n. 8882.

97 Cfr. Cons. Stato 2199/2002 cit., según el cual en el control débil el juez utiliza los conocimientos técnicos adquiridos gracias al perito técnico "con la única finalidad de efectuar un control de racionalidad y coherencia de la decisión administrsativa”; con la misma lógica, el Cons. Stato, sez. VI, 18 giugno 2002, n. 5156, ha afirmado que "el juez administrativo sólo puede verificar si el procedimiento impugnado tiene un contenido lógico, congruente, razonable, está correctamente motivado y tramitado, pero no puede sustituir con valoraciones de oportunidad propias las realizadas por la Autoridad de garantía de la competencia, ya que estas decisiones están reservadas a la Autoridad. Se trata, por tanto, de un control de tipo débil.

98 Cons. Stato, sez. VI, 2 marzo 2004, n. 926. 
se impone al juez la imposibilidad de tratar de ejercer el poder que el legislador ha atribuido a la administración ${ }^{99}$.

No obstante la progresiva ampliación de los poderes del juez administrativo para poder controlar las valoraciones técnicas de la administración, aún es dudoso que exista una equiparación plena en este punto con respecto al juicio civil (en el que, como se ha dicho, la valoración técnica realizada por el juez a través de sus peritos puede sustituir a la realizada por la administración).

\section{EL PRINCIPIO DE PROPORCIONALIDAD: ¿HACIA MODELO DIFERENTE DE SANCIÓN ADMINISTRATIVA?}

Del examen de los principales aspectos de la ley general sobre las sanciones administrativas resulta de forma bastante clara que el legislador de 1981 ha tratado de recurrir a los principios y reglas generales de la regulación penal. No obstante, en razón de la diversidad del cuadro constitucional de referencia esta equiparación no se ha logrado plenamente, pero es indudable que hoy la sanción administrativa constituye en Italia un instrumento jurídico funcionalmente homogéneo con respecto a la sanción penal: ambas se basan en la relación automática entre infracción y pena.

Como en todas las duplicidades hay que preguntarse si no existe algo de superfluo. A diferencia de las penales, las sanciones administrativas permiten favorecer -a cambio de una menor garantía para el interesado- el aspecto de la eficacia y de la inmediatez de la pena. No es por casualidad que las sanciones administrativas se hayan convertido en una de las mayores formas de actuación de muchas administraciones.

Esto no significa que esta forma de intervenir sea siempre la mejor respuesta a las exigencias de una correcta administración en determinados ámbitos de la vida de los ciudadanos o de la economía. En ocasiones las exigencias pueden ser diversas y requerir que la administración actúe a través de un instrumento más dúctil que permita tener en cuenta, por ejemplo, las dificultades técnicas de la normativa a aplicar o de otras condiciones particulares, determinando la no aplicación de la sanción según las concretas apreciaciones.

Creo que estas exigencias están cada vez mas presentes en el derecho comunitario, en particular mediante la aplicación del principio de proporcionalidad también en este sector. Como ha afirmado la Corte de Justicia precisamente en referencia a las sanciones administrativas, el principio de proporcionalidad "constituye un principio general del derecho comunitario" ${ }^{100}$. Este principio "exige que las instituciones comunitarias no excedan los límites de aquello que es idóneo y necesario para la con-

99 Cons. Stato, sez. VI, 8 febrero 2007, n. 515.

100 Corte justicia. 17 enero 2008, pleno C-37/06 e C-58/06, según la cual el principio “debe ser respetado en cuanto tal ya sea por el legislador comunitario ya sea por el legislador y los jueces nacionales que 
secución de los fines legítimamente perseguidos por la norma de que se trate, teniendo en cuenta que siempre que sea posible una opción entre medidas apropiadas, se debe recurrir a la menos restrictiva y que los perjuicios causados no deben ser desproporcionados respecto a los fines perseguidos" ${ }^{101}$. El principio de proporcionalidad no priva a los Estados miembros del poder seleccionar las sanciones más adecuadas con el fin de garantizar los objetivos del derecho comunitario (por ejemplo los de las directivas), pero esta selección debe producirse manteniendo siempre el equilibrio entre la medida de la sanción y la gravedad de la infracción, con la consecuencia de que "las medidas administrativas o represivas no deben sobrepasar los límites de aquello que es estrictamente necesario para los objetivos perseguidos, de modo que una sanción no puede ser tan desproporcionada respecto de la gravedad de la infracción de modo que pueda llegar a convertirse en un obstáculo a las libertades sancionadas en el Tratado"102.

Hoy el ámbito de aplicación del principio no está limitado a la aplicación de las normas derivadas del derecho comunitario (que por cierto son numerosísimas). De hecho después de la reforma introducida por la ley constitucional 3/200103 la proporcionalidad puede ser considerada un parámetro "interpuesto" de legitimidad constitucional a aplicar a toda la legislación italiana.

En este contexto la proporcionalidad deviene un principio de aplicación general que impone un sistema sancionador capaz de adaptarse a la gravedad de las infracciones y de no perder nunca de vista la finalidad perseguida por la regulación normativa. Si esto es así, hay que pensar en un sistema en el que la administración puede no aplicar la sanción si ésta, atendiendo a la gravedad del hecho o a las circunstancias concurrentes, puede devenir inútil o perjudicial para el interés protegido. Por otro lado se trata de casos en los que, al menos en un primer momento, la obligación de respetar lo previsto en la normativa sectorial aplicando lo dispuesto en los preceptos concretos puede llevarse a cabo a través de mas de una intervención punitiva con las que asegurar la adecuación de la actividad a los fines del derecho comunitario y nacional.

Se trata de una realidad que empieza a surgir cada vez de forma más frecuente, principalmente en las normas de aplicación del derecho comunitario. Por ejemplo, se excluye la aplicación de algunas sanciones en materia de seguros en supuestos de

aplican el derecho comunitario". "este principio también debe ser respetado por las autoridades nacionales competentes en lo referente a la aplicación” del derecho comunitario.

101 Corte justicia. C-37/06 e C-58/06 cit.

102 Corte justicia. 12 luglio 2001, C-262/99.

103 En base a la nueva redacción del art. 117, 1, Cost. «la potestad legislativa se ejercita por el Estado y por las Regiones respetando la Constitución, así como sujeta a los vínculos que derivan del ordenamiento comunitario y de las obligaciones internacionales". En base a esta disposición - a partir de la sentencia de la Corte cost. 24 ottobre 2007, n. 348- la Corte constitucional considera el derecho comunitario (además del internaciona, en particular la Convención europea de los derechos del hombre) como un parámetro interpuesto para valorar la constitucionalidad de las leyes nacionales. 
"absoluta falta de perjuicio" para los intereses protegidos ${ }^{104}$. Lo mismo ocurre con las sanciones administrativas en materia de tutela de la competencia y el mercado cuando exista una "cualificada colaboración" del responsable de la infracción en la identificación de la infracción ${ }^{105}$, así como en la sanciones en materia de calidad de los alimentos cuando el responsable acepte los requerimientos exigidos en fase de instrucción ${ }^{106}$.

Es manifiesta la diversidad de planteamiento respecto de un sistema basado sobre el binomio mecánico infracción-sanción administrativa. Hace falta comprender entonces si este nuevo escenario es compatible con la configuración del sistema sancionador que surge, por un lado, de la Constitución y, por otro, de la ley $689 / 1981$.

Desde el primer punto de vista no creo que se pueda dudar de la legitimidad constitucional de la reglas con un contenido similar al de las normas que acabamos de exponer. La reserva de ley aplicable a las sanciones administrativas (artículo 23 de la Constitución) no excluye ciertamente la posibilidad de que, siempre que sea dentro de los espacios previamente definidos por la ley, la administración pueda valorar ante el caso concreto la utilidad de la intervención sancionadora. Ni tampoco, desde otro punto de vista, existe para las sanciones una obligación de ejercer la potestad sancionadora idéntica a la que existe para el ministerio público en el ámbito de las sanciones penales (artículo 112 de la Constitución).

En este sentido se puede afirmar que las intervenciones normativas antes descritas son constitucionalmente legítimas y que, por otra parte, de iure condendo no existe ningún obstáculo para reproducir una formulación similar en otros sistemas sancionadores.

El problema se reproduce, pero desde otro punto de vista, es decir de iure condito, en aquellos sectores en los que no hay previsto nada al respecto y sólo es de aplicación la ley 689/1981. En estos casos el discurso debe cambiar, precisamente atendiendo al modelo sancionador fuertemente simplificado que resulta de la ley (al menos en la interpretación que hasta ahora ha realizado la jurisprudencia). Esto no obstante, llegar a la conclusión de que la administración no tiene ninguna posibilidad de valorar la oportunidad de la intervención sancionadora, debiendo siempre aplicar una sanción a la infracción, sería seguramente una conclusión simplificada.

Con este fin se afirma generalmente que, si está previsto de forma expresa en la norma que al graduar la sanción entre el mínimo y el máximo la administración puede tener en cuenta "la actitud del infractor para eliminar o atenuar las consecuencias de la infracción” y "la gravedad de la infracción” (artículo 11 de la ley), por el contrario

104 Cfr. l'art. 326, 1, decreto legislativo 7 septiembre 2005, n. 262.

88105 Cfr. l'art. 15, 2-bis, ley 287/1990.

106 Cfr. l'art. 8, 2, decreto legislativo 16 mayo 1997, n. 155. 
estaría excluida la posibilidad de no aplicar la sanción en el caso de comprobarse la existencia del comportamiento infractor.

Debe no obstante examinarse con atención el siguiente aspecto. Como se ha dicho, una jurisprudencia consolidada sostiene que la apreciación del elemento psicológico (dolo o culpa) puede ser presunta. Esta presunción, si bien es relativa (ya que admite prueba en contrario), ha provocado que la comprobación del ilícito administrativo se reduzca de forma esencial a la comprobación del hecho, sin dar relevancia alguna al elemento psicológico. Desde otra perspectiva, si se quisiera mantener la subsistencia de la presunción de culpabilidad -la cual cosa es dudosa a la luz de lo dispuesto en el artículo 3 de la ley 689/1981- habría que tener en cuenta que la misma convierte en facultativa, pero no impide, la investigación de estos aspectos por parte de la administración.

Al margen de los casos de infracción dolosa la administración tiene siempre la posibilidad de valorar la existencia e intensidad de la culpa, excluyendo en consecuencia la aplicación de la sanción en los caos en que se aprecie la inutilidad de la intervención sancionadora (por ejemplo, porque la infracción no ha sido fruto ni de negligencia ni de imprudencia, ni de impericia o porque aparece la buena fe del infractor $^{107}$, especialmente en los casos en los que el hecho ni siquiera ha alcanzado un nivel apreciable de perjuicio para el bien jurídico protegido). Se trata, no obstante, de una investigación que no puede ser llevada a cabo por primera vez, a iniciativa del infractor, dentro del eventual juicio de oposición, ya que debe ser la administración y no el juez la que deba valorar el elemento psicológico en relación a los fines perseguidos por la norma.

Son evidentes las razones que convierten en la práctica una investigación de este tipo en algo muy dificultoso, especialmente si se considera que la praxis de casi treinta años ha sido exactamente la contraria. No está claro, por otra parte, que esta investigación sea posible en relación a todos los sectores en los que están previstas sanciones administrativas. Se trata, en todo caso, de un problema que requerirá tener en cuenta la posible aplicación al mismo del principio de proporcionalidad.

\section{BIBLIOGRAFÍA DE REFERENCIA}

AA.VV., Le sanzioni amministrative, Atti del XXVI Convegno di Studi di Scienza dell'amministrazione-Varenna 1980, Milano, 1982.

AA.VV., Commentario alle modifiche al sistema penale, Milano, 1982.

AA.VV., La responsabilità amministrativa degli enti, Milano, 2002.

AA.VV., I modelli organizzativi ex d.Igs. 231/2001. Etica d'impresa e punibilità degli enti, Milano, 2005.

107 Un apunte en este sentido se encuentra en Corte de justicia,sez. VI, 12 julio 2001, C-262/99. 
Antonioli M., Legge antitrust, giurisdizione esclusiva e sanzioni amministrative al vaglio delle sezioni unite, in Foro amm.-CDS, 2005, pp. 2472 y ss.

Cannada Bartoli E., Illecito (dir. amm.), in Enc. dir., XX, Milano, 1970, p. 112 y ss.

Capaccioli E., Principi in tema di sanzioni amministrative: considerazioni introduttive, in AA.VV., Le sanzioni in materia tributaria, Milano, 1979, pp. 125 y ss.

Casetta E., Sanzione amministrativa, in Dig. disc. pubbl., vol. XIII, Torino, 1997, pp. 598 yss.

Cerbo P., Le sanzioni amministrative, Milano, 1999; Id., Le sanzioni amministrative, in Trattato di diritto amministrativo (a cura di) Cassese S., Parte speciale, vol. I, Milano, 2003, II ed., p. 579; Id., Le sanzioni amministrative, in Dizionario di diritto pubblico (a cura di), Cassese S. e altri, vol. VI, Milano, 2006, pp. 5422 y ss.

Moderne F., La sanction administrative (éléments d'analyse comparative), in Rev. fr. dr. adm., 2002, pp. 483 y ss.

Padovani T., La distribuzione di sanzioni penali e sanzioni amministrative secondo l'esperienza italiana, in Riv. it. dir. proc. pen., 1984, pp. 952 y ss.

Paliero C.E.-Travi A., La sanzione amministrativa. Profili sistematici, Milano, 1988.

Sandulli M.A., Le sanzioni amministrative pecuniarie, Napoli, 1983.

Scoca F.G., Giudice amministrativo ed esigenze del mercato, in Dir. amm., 2008, 257.

Severini G., Sanzione amministrativa (processo civile), in Enc. dir., app. VI, Milano, 2002, pp. 1005 y ss.

Tesauro A., Le sanzioni amministrative punitive, Napoli, 1925.

Travi A., Sanzioni amministrative e pubblica amministrazione, Padova, 1983; Id., La giurisdizione amministrativa per le sanzioni pecuniarie previste dal testo unico delle leggi in materia bancaria e creditizia, in Banca, borsa tit. cred., 2002, p. 378; Id., Giudice amministrativo e autorità indipendenti: il caso del sindacato sugli atti dell'autorità antitrust, in An. giur. ec., 2002, pp. 425 y ss.

Zanobini G., Le sanzioni amministrative, Torino, 1924.

Zoppini A., Imputazione dell'illecito penale e "responsabilità amministrativa" nella teoria della persona giuridica, in Riv. soc., 2005, pp. 1314 y ss. 